
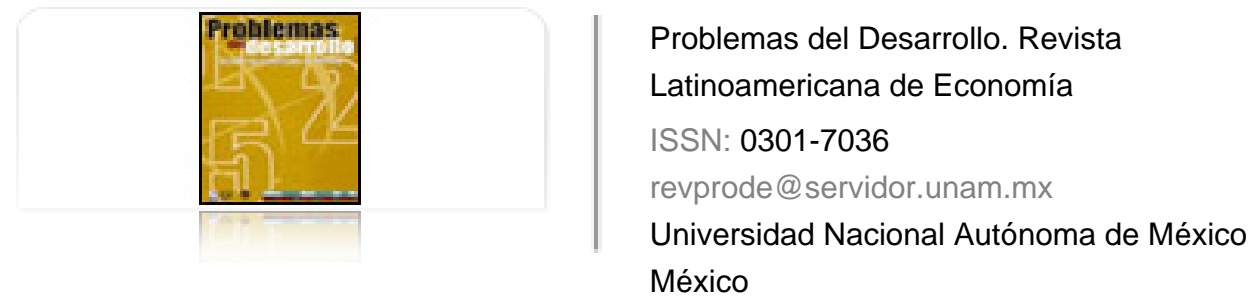

Wainer, Andrés

Más allá del consejo monetario: grandes empresas

Problemas del Desarrollo. Revista Latinoamericana de Economía, vol. 42, núm. 164, enero-marzo,

2011, pp. 99-126

Universidad Nacional Autónoma de México

Distrito Federal, México

Disponible en: http://www.redalyc.org/articulo.oa?id=11819774007

Cómo citar el artículo

- Número completo

- Más información del artículo

Página de la revista en redalyc.org

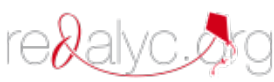

Sistema de Información Científica

Red de Revistas Científicas de América Latina, el Caribe, España y Portugal Proyecto académico sin fines de lucro, desarrollado bajo la iniciativa de acceso abierto 


\title{
Más allá del CONSEjo MONETARio: GRANDES EMPRESAS
}

\begin{abstract}
Andrés Wainer*
Fecha de recepción: 31 de agosto de 2010. Fecha de aceptación: 3 de noviembre de 2010.
\end{abstract}

\begin{abstract}
RESUMEN
En el presente artículo se analiza el desempeño de las empresas más grandes de la Argentina a partir del abandono del régimen de convertibilidad en el año 2002. El objetivo es analizar las continuidades y rupturas en el proceso de concentración y extranjerización que la economía argentina sufrió en los años noventa y el impacto diferencial de la nueva política económica sobre los distintos tipos de empresas. El análisis comienza en el año 1998, siendo que en dicho año se inició la crisis económica que culminó con la instauración de un nuevo régimen macroeconómico a partir de la devaluación de la moneda en el año 2002.

Palabras clave: Argentina, posconvertibilidad, grandes empresas, concentración económica, extranjerización
\end{abstract}

\section{BEYOND THE CURRENCY BOARD: BIG COMPANIES}

\section{Summary}

In this article, we analyze the performance of the largest companies in Argentina based on the abandonment of the currency convertibility system in 2002. The objective is to analyze continuities and breaks in the concentration and "foreignization" process which the Argentine economy suffered in the 1990s and the differential impact of the new economic policy on specific types of companies. The analysis starts with the year 1998, which was when the economic crisis began, culminating in the implementation of a new macroeconomic system based on the currency devaluation of 2002.

Key words: Argentina, post-convertibility, large companies, economic concentration, "foreignization".

* Sociólogo. Investigador del Área de Economía y Tecnología de la Facultad Latinoamericana de Ciencias Sociales (FlaCso), Argentina. Correo electrónico: andres.wainer@gmail.com. El autor agradece los valiosos comentarios de Daniel Azpiazu, Martín Schorr y los evaluadores anónimos. Desde ya, se los exime por los errores u omisiones que pudieran existir. 


\section{AU DELÀ DU CONSEIL MONÉTAIRE : GRANDES ENTREPRISES \\ Résumé}

Dans cet article, il est fait une analyse du comportement des entreprises les plus grandes d'Argentine à partir de l'abandon du régime de convertibilité en 2002. Lobjectif est d'analyser les continuités et les ruptures dans le processus de concentration et d'aliénation au profit d'intérêts étrangers que l'économie argentine a souffert dans les années quatre-vingt-dix et l'impact différentiel de la nouvelle politique économique sur les divers types d'entreprises. L'analyse commence en 1998, vu que c'est cette année-là que commence la crise économique qui aboutit à l'instauration d'un nouveau régime macroéconomique à partir de la dévaluation de la monnaie en 2002.

Mots clés : Argentine, post-convertibilité, grandes entreprises, concentration économique, aliénation au profit d'intérêts étrangers

\section{PARA ALÉM DO CONSELHO MONETÁRIO: GRANDES EMPRESAS \\ Resumo}

No presente artigo se analisa o desempenho das maiores empresas da Argentina a partir do abandono do regime de convertibilidade no ano de 2002. O objetivo é analisar as continuidades e rupturas no processo de concentração e desnacionalização que a economia argentina sofreu nos anos noventa e o impacto diferencial da nova política econômica sobre os distintos tipos de empresas. A análise começa no ano de 1998, sendo que nesse ano se iniciou a crise econômica que culminou com a instauração de um novo regime macroeconômico a partir da desvalorização da moeda no ano de 2002.

Palavras-chave: Argentina, pos-convertibilidade, grandes empresas, concentração econômica, desnacionalizaçấo.

超越货币委员会：大公司

摘要

本文分析了阿根廷自2002年放弃兑换制度后一些大公司的情况。其目的 是分析阿根廷经济90年代在集中与国际化过程中所面临的连续性和破裂 以及新经济政策对不同类型企业的影响。

分析开始于1998年。当年所开始的经济危机引起了2002年的货币贬值 和新宏观经济制度的建立。

关键词：阿根廷，可兑换后期，大型企业，经济集中，外国所有权 


\section{INTRODUCCIÓN}

En la última década se han suscitado importantes cambios a nivel político y económico en América Latina. Con mayor o menor intensidad, buena parte de los países latinoamericanos adoptaron políticas que fueron alejándose de las premisas del "Consenso de Washington", especialmente tras las negativas consecuencias económico-sociales que generaron las reformas neoliberales aplicadas durante los años noventa. En términos generales, en los últimos años la región logró obtener importantes tasas de crecimiento económico y cierta mejora en los principales indicadores sociales. Sin embargo, en las economías más importantes del subcontinente (Brasil, México, Argentina) no parece vislumbrarse un nuevo proceso de desarrollo económico endógeno que permita revertir completamente los críticos legados del neoliberalismo en América Latina.

Mientras que en México los alcances de los cambios político-sociales han sido más limitados y se ha priorizado la continuidad con procesos anteriores, en Brasil el cambio político y en términos de políticas sociales fue más significativo, pero la política económica en dicho país se ha mantenido sin grandes transformaciones. ${ }^{1}$ En el caso particular de la Argentina, el abandono del régimen de convertibilidad en el año 2002 implicó cambios sustantivos a nivel macroeconómico que tuvieron un fuerte impacto en el desempeño de los distintos sectores de la economía y, por ende, entre las distintas fracciones capitalistas. Si el modelo de convertibilidad durante los años noventa benefició mayormente a las empresas de servicios públicos privatizadas y los grandes bancos privados, ${ }^{2}$ la devaluación de la moneda y los cambios en el patrón de crecimiento a partir de 2002 determinaron que estas fracciones quedasen relativamente rezagadas. A contramano de lo ocurrido durante la vigencia del régimen de convertibilidad, las principales favorecidas por la política económica a partir de 2002 han sido las fracciones del capital productivo. ${ }^{3}$

1 Sobre los cambios y continuidades en los procesos económicos en México y Brasil ver, entre otros, Cooney y Mariña Flores (2008), Cooney (2007a y 2007b) y Vidal (2008).

2 El "Plan de Convertibilidad" fue instaurado en septiembre de 1991 por el entonces ministro de Economía Domingo Cavallo; consistía, básicamente, en la adopción de un tipo de cambio fijo por ley y el condicionamiento de la emisión monetaria a la evolución de las reservas internacionales. Al respecto consultar, entre otros, Azpiazu, Forcinito y Schorr (2001), Basualdo (2006), Peralta Ramos (2007) y Torre y Gerchunoff (1996).

3 Sobre los principales cambios en el patrón de crecimiento durante la posconvertibilidad consultar, entre otros, CENDA (junio 2007), Damill y Frenkel (2009), Lanteri (2009) y Varesi (2010). 
Sin embargo, durante la posconvertibilidad también se han registrado continuidades significativas; a pesar de la reivindicación que se hizo desde los elencos gubernamentales sobre la necesidad de recuperar un empresariado nacional fuerte, el peso del capital extranjero entre las más grandes empresas productoras de bienes de la economía argentina no sólo no ha disminuido sino que se ha acrecentado. Esto es sumamente relevante teniendo en cuenta que, al igual que el resto de los países latinoamericanos, la Argentina es una economía dependiente y, por lo tanto, su proceso de acumulación está determinado en lo sustantivo por el papel de las grandes empresas trasnacionales y por el flujo de capitales desde el exterior.

Si bien a fines de los años cincuenta y durante la década de 1960 las empresas multinacionales eran visualizadas como potenciales agentes de desarrollo, ya que se suponía -y efectivamente sucedió en algunos casos- que estaban en condiciones de realizar importantes inversiones para modernizar las estructuras productivas, ${ }^{4}$ en la actual etapa de globalización la creciente presencia de compañías extranjeras obedece más a un proceso de desnacionalización, concentración y centralización económica que a la generación de nuevas empresas "desde cero" (greenfield) y/o al desarrollo de nuevas ramas industriales. En efecto, el rol de las filiales de las empresas trasnacionales se ha visto sustancialmente modificado en la presente etapa, siendo que en la mayor parte de los casos no procuran desarrollar nuevas ramas y sectores que permitirían darle mayor densidad a la "matriz insumo-producto" sino que son parte de un sistema de producción trasnacionalizado que no necesariamente depende de la demanda interna. ${ }^{5}$

Teniendo en cuenta este contexto, el objetivo de este artículo es analizar la evolución reciente del proceso de concentración y centralización del capital en la Argentina a partir del desempeño de las más grandes empresas durante la posconvertibilidad. Para ello, siguiendo la línea inaugurada por trabajos antecedentes sobre la cúpula empresaria, ${ }^{6}$ se han considerado diversas variables vinculadas con las doscientas firmas con mayores ventas del sector no financiero, a lo cual

4 Sobre el rol de las empresas trasnacionales entre fines de la década del cincuenta y mediados de los ańos setenta en la Argentina consultar, entre otros, Azpiazu (1986), Braun (1975) y Sourrouille (1976).

5 Al respecto ver Arceo (2001 y 2005).

6 Algunos de los más destacados trabajos sobre el rol de la cúpula empresaria durante las últimas dos décadas son los de Arceo, Azpiazu, Basualdo y Wainer (2009), Basualdo (2006) y Lozano, Rameri y Raffo (2009). 
se ha añadido el grupo de las diez entidades bancarias con mayores ingresos. ${ }^{7}$ La relevancia del análisis de esta cúpula empresaria está dado por el alto nivel de concentración económica existente en la Argentina, siendo que el desempeño de estas grandes compañías determina en buena medida el devenir económico del conjunto del país. ${ }^{8}$

El análisis comienza en el año 1998, ya que se trata del año en el cual se inició la crisis económica que terminaría con la salida del régimen de convertibilidad, y culmina en 2007 debido a la existencia de numerosos problemas con la información estadística posterior a dicha fecha. ${ }^{9}$ Los últimos cuatro años de vigencia de la convertibilidad (1998-2001) están en función de poder realizar una comparación con la situación relativa de las grandes empresas a partir del cambio del régimen macroeconómico operado en 2002. En definitiva, de lo que se trata es de identificar algunos de los importantes cambios y las continuidades que se registraron dentro del gran capital en el actual periodo de posconvertibilidad.

\section{LA EVOLUCIÓN DE LAS VENTAS DE LAS DISTINTAS FRACCIONES DEL GRAN CAPITAL}

El abandono del régimen de convertibilidad derivó en una mejora de los precios relativos de los bienes transables frente a los no transables e impulsó la recuperación de la demanda interna a partir de impulsar un nuevo, aunque acotado,

7 Al no registrar "ventas" en sus balances, y dado que los bancos operan con capitales ajenos, se procedió a construir un indicador que actuara de equivalente. A tal efecto, se consideró como ingresos al spread (diferencia de intereses entre tasas activas y pasivas) y lo que cobran las entidades en concepto de comisiones y servicios.

8 A modo de ejemplo, para dar cuenta de la importancia de esta cúpula empresaria basta mencionar que sólo las doscientas empresas más grandes del sector no financiero explicaron entre el $21.6 \%$ y el $23.1 \%$ del valor bruto de producción (a precios corrientes) del total de la economía argentina entre 1998 y 2001. Tras la devaluación de la moneda en 2002 el peso de esta cúpula se incrementó significativamente, pasando a explicar alrededor del $30 \%$ del valor bruto de producción de toda la economía.

9 En el año 2007 el Instituto Nacional de Estadísticas y Censos (INDEC), principal órgano estadístico de la Argentina, fue intervenido por el gobierno nacional. A raíz de esta intervención -en su mayor parte de carácter informal-, se produjo una creciente desconfianza en la calidad de las estadísticas elaboradas por dicho organismo, especialmente en lo que hace referencia a la evolución de los precios internos. 
proceso de sustitución de importaciones, a la vez que favoreció un incremento de las ventas externas a través de una mejora en la competitividad de las firmas exportadoras. Todo ello conllevó un aumento de las ventas de los sectores productores de bienes que benefició sustancialmente a las grandes empresas. ${ }^{10}$ Por el contrario, las empresas de servicios públicos y los bancos vieron mermar sus ingresos como consecuencia del relativo estancamiento de las tarifas y la reducción de la tasa de interés.

El primer elemento importante que hay que considerar al analizar el desempeño de las grandes empresas en la Argentina es la cantidad de firmas que integran la cúpula empresaria de acuerdo con la fracción a la que pertenecen (Cuadro 1).

Cuadro 1. Cantidad de empresas de la cúpula empresaria según sector de actividad, 1998-2007 (valores absolutos)

\begin{tabular}{lrrrrrrrrrr}
\hline & 1998 & 1999 & 2000 & 2001 & 2002 & 2003 & 2004 & 2005 & 2006 & 2007 \\
\hline Agroindustriales & 39 & 37 & 39 & 38 & 44 & 41 & 44 & 38 & 34 & 30 \\
Comerciales & 36 & 37 & 35 & 35 & 27 & 32 & 33 & 35 & 37 & 34 \\
Constructoras & 2 & 2 & 2 & 2 & 1 & 1 & 1 & 1 & 1 & 2 \\
Holdings (diversificadas) & 3 & 2 & 2 & 1 & 2 & 1 & 1 & 1 & 1 & 1 \\
Industriales (resto) & 67 & 61 & 57 & 58 & 62 & 57 & 63 & 61 & 63 & 69 \\
Petroleras y mineras & 13 & 15 & 17 & 16 & 23 & 25 & 22 & 24 & 21 & 21 \\
Servicios & 40 & 46 & 48 & 50 & 41 & 43 & 36 & 40 & 43 & 43 \\
Bancos & 10 & 10 & 10 & 10 & 10 & 10 & 10 & 10 & 10 & 10 \\
Total & 210 & 210 & 210 & 210 & 210 & 210 & 210 & 210 & 210 & 210 \\
\hline
\end{tabular}

Fuente: Elaboración propia con base en información del Área de Economía y Tecnología de la FlacSO y las revistas Prensa Económica y Mercado.

Como se puede observar, en la posconvertibilidad se han registrado ciertos cambios relevantes en el tipo de empresas que integran el ranking, destacándose

10 Sobre el desempeño de las exportaciones argentinas en este periodo consultar, entre otros, Bekerman y Cerdeiro (2007), CENDA (junio 2007), Damill y Frenkel (2009) y González y Rodríguez (2007). 
un fuerte crecimiento de la cantidad de firmas petroleras y mineras y, en promedio, una menor proporción de empresas de servicios. Contrariamente a lo que se podría suponer dado el repunte de la actividad industrial, ${ }^{11}$ no ha habido un aumento significativo de la cantidad total de firmas manufactureras en la cúpula empresaria. Si bien el nuevo escenario macroeconómico favoreció a las actividades productivas en detrimento de los servicios, en términos de empresas de la cúpula el lugar que dejaron vacante estos últimos ha sido ocupado por las firmas petroleras y mineras. Más allá de mínimos vaivenes, la cantidad de firmas de este tipo entre las doscientas más grandes aumentó significativamente desde 1998 en adelante gracias a mayores niveles de facturación debido al aumento de los precios absolutos y relativos del petróleo y los minerales (Cuadro 2) y a la incorporación de nuevas empresas mineras en el ranking. La estabilidad en la cantidad de firmas manufactureras en la cúpula empresaria y el incremento del número de compañías petroleras y mineras son un importante indicador de una tendencia hacia la "reprimarización" de la economía argentina. ${ }^{12}$

Es un hecho que el impacto de la devaluación de la moneda no ha sido igual para todos los sectores. ${ }^{13}$ El nuevo esquema de precios relativos producido por la devaluación y el congelamiento de tarifas dictaminado por el gobierno de Duhalde a comienzos del año 2002 implicaron un retraso sustancial de los precios de los servicios respecto al resto de la economía. En cambio, durante los años noventa, la conjunción de apertura externa y un tipo de cambio crecientemente sobrevaluado había generado una fuerte presión a la baja sobre los precios de los bienes transables debido a la competencia de las importaciones, mientas que la mayor parte de los precios de los bienes no transables, especialmente los servicios públicos privatizados y la tasa de interés, no sólo se habían mantenido sino que se habían incrementado en términos reales. Es por ello que se puede afirmar que el actual es un esquema de precios relativos casi opuesto al de la convertibilidad.

\footnotetext{
$11 \mathrm{Al}$ respecto ver Azpiazu y Schorr (2010) y CENDA (diciembre 2007b).

12 Cabe señalar que no sólo se asiste a un proceso de reprimarización de la estructura económica en general sino también dentro de la propia industria, donde las grandes firmas se han convertido en buena medida en "ensambladoras" o productoras de bienes intermedios de uso difundido. Al respecto ver Azpiazu y Schorr (2010).

13 Para analizar la evolución de los precios relativos en la posconvertibilidad debe tenerse en cuenta el efecto inflacionario de la devaluación de la moneda en una estructura productiva como la argentina. Al respecto ver Diamand (1973), Braun (1975) y Braun y Joy (1981).
} 
Cuadro 2. Evolución de los precios de los distintos sectores de la economía argentina, 1998-2007 (en número índice base 1993=100)

\begin{tabular}{lcccc}
\hline & Agropecuarios & Manufacturas & Servicios públicos & Minerales y Petróleo \\
\hline 1993 & 100 & 100 & 100 & 100 \\
1994 & 96 & 101 & 106 & 94 \\
1995 & 100 & 107 & 111 & 105 \\
1996 & 110 & 109 & 115 & 127 \\
1997 & 105 & 111 & 121 & 120 \\
1998 & 101 & 109 & 122 & 87 \\
1999 & 85 & 106 & 125 & 114 \\
2000 & 84 & 107 & 126 & 171 \\
2001 & 82 & 107 & 127 & 147 \\
2002 & 171 & 174 & 132 & 331 \\
2003 & 206 & 208 & 134 & 404 \\
2004 & 213 & 223 & 136 & 468 \\
2005 & 212 & 242 & 138 & 565 \\
2006 & 231 & 263 & 139 & 710 \\
2007 & 268 & 298 & 144 & 702 \\
\hline
\end{tabular}

Fuente: Elaboración propia en base a INDEC y CEPAL.

Sin embargo, tal como se puede observar en el cuadro precedente, no todos los precios de los bienes transables aumentaron por igual. Si bien a nivel internacional los precios de los productos agropecuarios aumentaron mucho más que los de las manufacturas, la diferencia entre unos y otros en el mercado interno no fue tan significativa gracias a la imposición de retenciones a las exportaciones (variables según los distintos productos). Justamente, un objetivo de la aplicación de retenciones a las exportaciones es la de "desligar" los precios internos de los internacionales ya que en muchos casos se trata de bienes que son esenciales para los consumidores en el mercado interno, como la carne y el trigo. ${ }^{14}$ Este distinto esquema de precios relativos, como era de esperar, tuvo un fuerte impacto en la facturación de las grandes empresas (Gráfica 1).

14 Las retenciones a las exportaciones consisten básicamente en la aplicación de una alícuota a las exportaciones de determinados productos, de modo que el productor/exportador recibe un precio inferior al vigente a nivel internacional. Esta diferencia entre el precio internacional y el precio interno genera un ingreso fiscal extraordinario para el Estado. 
Gráfica 1. Evolución de los ingresos por sector de la cúpula empresaria, 1998-2007 (en millones de pesos de 2005)

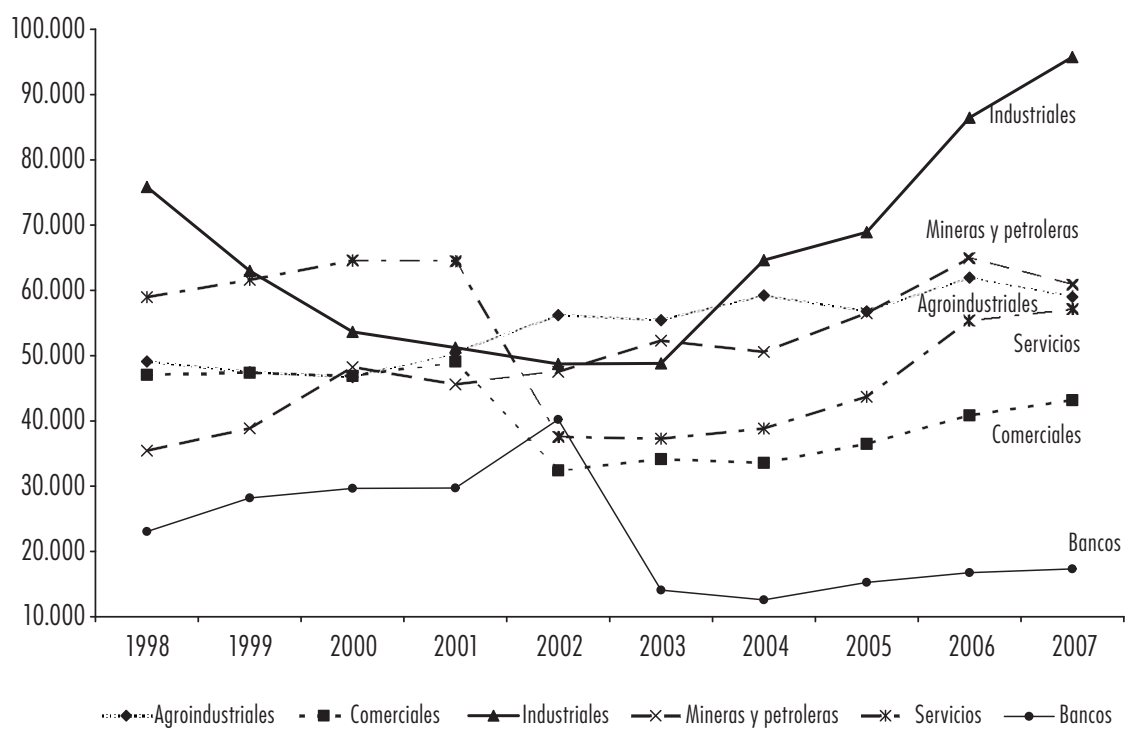

Fuente: Elaboración propia con base en información del Área de Economía y Tecnología de la Flacso, las revistas Prensa Económica y Mercado y BCRA.

Efectivamente, el abandono de la convertibilidad implicó un fuerte cambio de tendencias en las ventas de las distintas fracciones y subfracciones de la cúpula empresaria. En primer lugar, se destaca como "atípico" el primer año de la posconvertibilidad (2002), ya que mientras una parte de las fracciones empresarias vio desplomar su facturación, lo cual era de esperar teniendo en cuenta que el PBI se contrajo un $10.9 \%$, hubo tres tipos de empresas que aumentaron sus ingresos: las firmas agroindustriales, las mineras y petroleras y los bancos. ${ }^{15}$

Como se mencionó, en el caso de las compañías petroleras y mineras, el crecimiento de la facturación se debió exclusivamente al aumento de los precios internacionales del petróleo y los minerales, ya que las cantidades vendidas cayeron un $4 \%$ entre 2001 y 2007. En el caso de las firmas agroindustriales, la

15 Cabe aclarar que las grandes empresas con estructuras altamente diversificadas (holdings) han quedado fuera del análisis por la imposibilidad de ser clasificadas en alguna de las categorías empleadas y por su escaso peso sobre el total: este tipo de firmas representó menos del $1 \%$ de las ventas totales de la cúpula empresaria entre 2002 y 2007. 
tendencia ascendente también es explicada por la recuperación de los precios internacionales de la mayor parte de los principales productos; el "efecto precio" se hace evidente cuando las ventas de la subfracción agroindustrial son deflactadas por el correspondiente índice de precios sectorial; tras un excepcional aumento de casi el 50\% en el año 2002 respecto a 2001, las cantidades vendidas (considerando la evolución de los precios sectoriales) se mantuvieron más o menos constantes entre 2002 y 2007.

Sin duda, una de las cuestiones más llamativas de la gráfica sobre la evolución de los ingresos es el desempeño de los bancos en 2002, ya que a priori podría suponerse que estos fueron unos de los principales perjudicados por el default de la deuda y la devaluación. ${ }^{16}$ En este sentido, el particular repunte en el año 2002 se debió fundamentalmente al aumento de los ingresos financieros de los bancos por la aguda subida de la tasa de interés, la cual, como resultado de la crisis de la deuda externa, del aumento del precio del dólar y de la inflación desatada a partir de la devaluación de la moneda, alcanzó en promedio un 53\% mensual (préstamos a empresas de primera línea). Sin embargo, a partir de 2003 la tasa de interés nominal comenzó a bajar abruptamente y luego se mantuvo a niveles muy inferiores a los registrados durante la convertibilidad. De hecho, la tasa de interés real llegó a ser negativa tanto en 2003 como en 2005 y $2006 .{ }^{17}$

Mientras que el notable aumento de los ingresos que tuvieron los bancos en 2002 como consecuencia del alza de la tasa de interés no necesariamente implicó una mejora sustancial en el desempeño de las entidades -sino que se trató simplemente de una consecuencia del desenlace de la crisis económica y financiera-, por el contrario, la tibia recuperación que se vislumbra en los ingresos de las entidades financieras a partir de 2004 está asociada a un mayor volumen de negocios dado por la reactivación económica y al proceso de saneamiento del sistema financiero. ${ }^{18}$

Pero sin duda el desempeño más contrastante con lo ocurrido en los últimos años de la convertibilidad es el de empresas manufactureras (sin agroindustria).

16 Cabe recordar que a fines de diciembre de 2001 el entonces presidente provisional Adolfo Rodríguez Saá declaró el cese de los pagos del conjunto de la deuda pública a excepción de aquélla contraída con los organismos multilaterales de crédito (FMI, Banco Mundial y BID).

17 La tasa de interés real es calculada tomando como referencia la tasa activa en pesos a 30 días a empresas de primera línea y descontándole la variación de los precios minoristas (IPC). En todos los años mencionados la inflación superó dicha tasa de interés nominal (Ministerio de Economía).

$18 \mathrm{Al}$ respecto ver Cobe (2009). 
Si bien el aumento de los precios de los bienes transables incidió positivamente sobre la producción de las firmas industriales, el repunte de las ventas se vio influido también por la recuperación de la demanda agregada. Al considerar las ventas deflactadas por los precios del sector ("resto de industria"), se observa que las mismas crecieron entre 2001 y 2007 a una tasa anual acumulativa del 12\%. Esta notable recuperación de las ventas de la fracción industrial estuvo motorizada por la sustitución de importaciones y, muy especialmente, por el aumento de las exportaciones.

En este sentido, entre 2001 y 2007 la demanda interna de bienes nacionales creció en términos reales un 36\%, mientas que las ventas de la cúpula industrial lo hicieron en un $68.8 \%$. Esta diferencia entre el crecimiento de la demanda interna y el incremento de las ventas de las empresas industriales que integran la cúpula empresaria puede ser explicada por el aumento en el nivel de concentración de la economía y, fundamentalmente, por el comportamiento de las exportaciones de manufacturas de la elite industrial, las cuales pasaron de 4.308 millones de dólares en 2001 a 10.651 millones en $2007 .{ }^{19}$

Por el contrario, si bien también mostraron una tendencia ascendente -aunque mucho menor- desde 2003, la facturación de las firmas comerciales siguió muy por debajo de lo ocurrido a finales de la década de 1990. Este magro desempeño es explicado exclusivamente por las grandes cadenas comerciales, ya que las empresas comercializadoras de granos y aceites de origen vegetal vieron aumentar sus ingresos en todos los ańos de la posconvertibilidad, lo cual no debe llamar la atención ya que en su totalidad son firmas exportadoras que se vieron muy beneficiadas por la devaluación del peso y el favorable escenario internacional. De todos modos es posible que las cifras de las ventas del primer tipo de firmas comerciales, especialmente las supermercadistas y las cadenas de

19 Cabe resaltar que en la evolución de las exportaciones de las grandes firmas industriales de la cúpula empresaria desvinculadas de la producción agropecuaria tuvo una gran incidencia lo ocurrido con la industria automotriz, la cual aumentó sus ventas externas en un $175 \%$ entre 2001 y 2007, llegando a explicar en este último año el 48\% del total de las exportaciones de esta fracción empresaria. Si bien la industria automotriz a priori puede ser considerada como una actividad con alto valor agregado, debe tenerse en cuenta un elemento central al respecto: el automotriz fue casi el único sector que gozó de un régimen especial de promoción y protección durante toda la década de 1990 , pero como parte de este régimen especial las actividades de dicho complejo productivo prácticamente se circunscribieron a tareas de armaduría y/o ensamblado de partes con escasa producción propia. En efecto, con la salvedad del año 2002, la industria automotriz ha presentado en todos los años considerados saldos comerciales negativos (Azpiazu y Schorr, 2010). 
electrodomésticos, no reflejen completamente la recuperación del consumo registrada a partir de 2003 debido a que los precios minoristas se incrementaron significativamente más que los mayoristas, siendo estos últimos los utilizados en el cálculo. ${ }^{20}$

Pero, sin duda, la caída más espectacular, sólo comparable con la ocurrida con los bancos, es la de las empresas de servicios, cuya facturación se redujo significativamente en los primeros años de la posconvertibilidad para luego ir recuperándose, sobre todo a partir de 2006. Esta abrupta caída al comienzo de la etapa de posconvertibilidad se debió fundamentalmente al congelamiento de las tarifas y al mencionado cambio en los precios relativos. En efecto, aquí quedan en evidencia los asimétricos efectos del cambio en el patrón de crecimiento sobre los distintos tipos de firmas. Mientras que tanto los bancos como las compañías de servicios se habían visto beneficiados por el modelo de convertibilidad, al menos en un principio resultaron ser los más perjudicados por su abandono. Por el contrario, mientras que las grandes empresas industriales habían sido las más perjudicadas durante la convertibilidad -y especialmente en los últimos años-, en esta nueva etapa resultaron ser las más beneficiadas. De allí que se pueda sostener que durante la posconvertibilidad hubo cambios significativos en el desempeño de las distintas fracciones que conforman el gran capital en la Argentina.

\section{DIFERENCIAS EN LA PERFORMANCE DE LAS EMPRESAS NACIONALES Y EXTRANJERAS ${ }^{21}$}

Se ha visto que, en términos de ventas, el comportamiento de la mayor parte de las grandes empresas según la fracción del capital a la que pertenecen ha sido sustancialmente distinto a lo registrado durante la etapa de convertibilidad. Resta analizar ahora lo propio en función del origen de los capitales con el

20 Según el Instituto Nacional de Estadísticas y Censos (INDEC), las ventas de los supermercados en diciembre de 2006 alcanzaron el mismo nivel que en diciembre de 2001 (a precios constantes). En el caso de las cadenas de electrodomésticos, si se considera el índice de precios al consumidor, se observa que las mismas aumentaron sus ventas entre 2003 y 2006 a una tasa anual acumulativa del $54.3 \%$.

21 Se ha clasificado a las firmas como extranjeras, nacionales o estatales según el origen del accionista mayoritario o controlante. En los casos en que la propiedad de la empresa es compartida en partes iguales por capitales de distinto origen -y, en consecuencia, ningún accionista detenta el control de la firma-, se optó por denominarlas como empresas "mixtas". 
objetivo de visualizar continuidades o rupturas en el proceso de extranjerización vivido durante los ańos noventa. ${ }^{22}$ Este análisis cobra mayor relevancia, como se mencionó, teniendo en cuenta que la argentina es una economía dependiente.

Contrariamente a lo que se podría suponer a partir del resurgimiento en los elencos gubernamentales de discursos en favor de un "capitalismo nacional" y la reconstrucción de una "burguesía nacional", durante la posconvertibilidad el proceso de extranjerización, en lugar de revertirse se ha profundizado. La creciente incidencia del capital extranjero sobre el conjunto de la economía argentina $y$, particularmente, entre las grandes empresas no financieras, no ha detenido su marcha. $\mathrm{Al}$ respecto se presenta la siguiente gráfica con la evolución de la facturación de las doscientas mayores empresas del sector no financiero discriminadas según el origen de sus capitales. Vale aclarar que no se tomaron en consideración ni las empresas estatales ni las de capitales mixtos -es decir, de propiedad compartida en partes iguales por capitales locales y extranjeros- dada su escasa relevancia sobre el total de los ingresos. ${ }^{23}$

Tal como se observa en la Gráfica 2, la brecha que separa a las firmas extranjeras de las nacionales no sólo se mantuvo sino que se amplió durante la posconvertibilidad, con lo cual más que señalar una simple continuidad del proceso de extranjerización se debería hablar de su profundización. Mientras que las ventas de las empresas locales cayeron un $8 \%$ en pesos constantes entre 2001 y 2007 , en el caso de las firmas de capital extranjero aumentaron 33\%.

Como consecuencia de estos disímiles desempeños, las firmas extranjeras incrementaron sustancialmente su participación en los ingresos de la cúpula empresaria, pasando a representar más del 73\% de las ventas en 2007 frente al 66\%

22 Durante la década de 1990 el capital extranjero incrementó decisivamente su papel en la economía argentina. Este proceso tuvo un fuerte impacto especialmente entre las empresas más grandes del país. $\mathrm{Al}$ respecto basta mencionar que mientras que a comienzos de la década las ventas de las empresas nacionales del sector no financiero explicaban alrededor de dos tercios de la facturación total de la cúpula empresaria, en el año 2000 su participación se había reducido a un cuarto de la misma. Por el contrario, las empresas trasnacionales incrementaron su participación en una proporción similar pero inversa (Arceo, Azpiazu, Basualdo y Wainer, 2009). Un análisis detallado sobre el proceso de extranjerización entre las 500 más grandes empresas del sector no financiero durante la convertibilidad es el de Burachik (2010). Sobre el intenso proceso de extranjerización del sistema financiero consultar Bleger (2000).

23 Si bien, como se verá más adelante, la cantidad de empresas estatales se incrementó durante los últimos años, en todo el periodo considerado (1998-2007) la participación de las mismas en la facturación de la cúpula empresaria alcanzó un máximo de 1.6\% mientras que las firmas "mixtas" no superaron el $0.4 \%$. 
en 2001. Como contrapartida, la participación de las ventas de las firmas nacionales pasó del 32\% en 2001 al $24 \%$ en $2007 .{ }^{24}$

Gráfica 2. Evolución de las ventas por origen de capital de la cúpula empresaria (sector no financiero) y su tendencia, 1998-2007

(en millones de pesos de 2005)

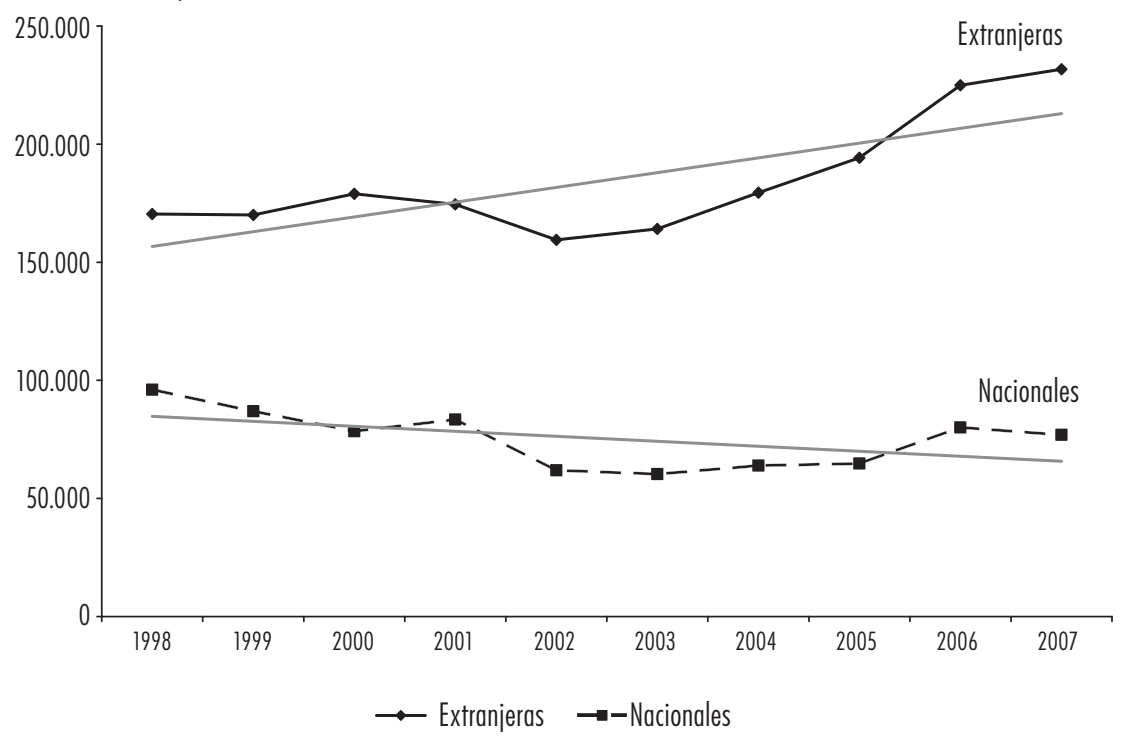

Fuente: Elaboración propia con base en información del Área de Economía y Tecnología de la Flacso y las revistas Prensa Económica y Mercado.

Lo que demuestran estos datos es que la tendencia a la extranjerización del gran capital en la economía argentina no se debió exclusivamente ni a un proceso de crisis, como la sufrida entre 1998-2002, ni tampoco a una etapa de crecimiento económico como la que se vivió entre 2003 y 2007. En este sentido, el proceso de extranjerización se debió principalmente a la incapacidad de las grandes empresas argentinas para competir en igualdad de condiciones con sus pares trasnacionales tras los procesos de apertura económica y de profunda desregulación de la economía impulsados durante los años noventa, reformas

24 La diferencia entre el total de las ventas y la participación de firmas nacionales y extranjeras es explicada por la participación de las empresas estatales y mixtas. 
estructurales que, en lo sustantivo y a pesar de la modificación del tipo de cambio, prácticamente no se revirtieron en la etapa de posconvertibilidad.

Este aumento de la participación de las ventas en la cúpula empresaria por parte de las empresas trasnacionales se debió a dos factores que concurrieron simultáneamente. Por un lado, se dio un aumento en la cantidad de firmas de origen extranjero en detrimento de las de origen local (Cuadro 3). Estos cambios se debieron principalmente a la continuidad del proceso de desnacionalización y sólo secundariamente al ingreso de nuevas firmas al ranking. ${ }^{25}$ En este mismo sentido, otro elemento que se destaca en la posconvertibilidad es el aumento en la cantidad de firmas estatales, lo cual se debe fundamentalmente a las reestatizaciones del Correo Argentino y de la empresa proveedora del servicio de agua en la ciudad de Buenos Aires, al ingreso al ranking de dos empresas de energía, y a la creación de una nueva petrolera estatal. De todos modos, cabe remarcar, la participación de las ventas de este tipo de firmas en el periodo 2002-2007 apenas alcanzó el $1.6 \%$ del total de la cúpula empresaria. ${ }^{26}$

Cuadro 3. Cantidad de empresas por origen de capital (sector no financiero) 1998-2007 (valores absolutos)

\begin{tabular}{lrrrrrrrrrr}
\hline & 1998 & 1999 & 2000 & 2001 & 2002 & 2003 & 2004 & 2005 & 2006 & 2007 \\
\hline Extranjeras & 114 & 120 & 127 & 123 & 133 & 131 & 130 & 131 & 126 & 133 \\
Nacionales & 84 & 77 & 70 & 74 & 65 & 64 & 65 & 64 & 68 & 59 \\
Estatales & 1 & 1 & 1 & 1 & 2 & 3 & 3 & 4 & 5 & 6 \\
Mixtas & 1 & 2 & 2 & 2 & 0 & 2 & 2 & 1 & 1 & 2 \\
\hline
\end{tabular}

Fuente: Elaboración propia con base en información del Área de Economía y Tecnología de la FlacSO y las revistas Prensa Económica y Mercado.

25 Esta desnacionalización incluyó la compra de las tenencias accionarias de algunas grandes firmas como los frigoríficos Swift, Finexcor y Quickfood, la cementera Loma Negra, la cervecería Quilmes, la siderúrgica Acindar y la textil Alpargatas. Sobre el particular, vale resaltar que buena parte de esas transferencias de capital hacia inversores extranjeros tuvieron como actor central a firmas brasileras que, en la generalidad de los casos, contaron con el apoyo financiero del Banco Nacional de Desenvolvimento Econômico e Social a través de líneas crediticias preferenciales orientadas a la "internacionalización de las empresas brasileras".

26 Para evaluar lo exiguo de dicho indicador basta con señalar que a mediados de la década de 1970 las empresas estatales explicaban más del 35\% de la facturación total de la cúpula empresaria, en tanto en 1989 (antes de las privatizaciones) dicho porcentaje se ubicaba en el 32\% (Azpiazu, Basualdo, Arceo y Wainer, 2009). 
En definitiva, lo que revela la continuidad del proceso de desnacionalización es la debilidad competitiva de la burguesía local en una economía abierta y ante la ausencia de políticas públicas que fomenten una reconversión estratégica de las firmas de capital nacional más allá de algunas previamente consolidadas (mayormente productoras de bienes intermedios de uso difundido). ${ }^{27}$ Sin duda, la sola modificación del tipo de cambio no ha alcanzado para revertir este proceso. ${ }^{28}$ Todo esto se ve reflejado tanto en la ininterrumpida fuga de capitales, como en el direccionamiento de inversiones hacia sectores donde el capital trasnacional aún no encontró una manera eficiente de controlar la producción desde sus países de origen -por ejemplo en el sector agropecuario-, o donde no existen significativas diferencias de productividad por el propio carácter de la actividad, como en el comercio.

Aún resta incluir en el análisis sobre el origen del capital los cambios en los ingresos de los diez bancos más grandes. Si bien los bancos como conjunto fueron perjudicados en un primer momento por el abandono del modelo de convertibilidad, al discriminar por origen de capital se observa que el desempeño no fue igual para todos los tipos de entidades (Gráfica 3).

En primer lugar, en la gráfica precedente se destaca la magnitud de la caída de los ingresos de las entidades extranjeras a partir de 2003. Dado que el año 2002 fue sumamente atípico por los súbitos cambios en los precios relativos que trajo aparejada la devaluación del peso argentino, en este punto conviene realizar las comparaciones con el último año de vigencia de la convertibilidad (2001). En este sentido, los ingresos de los bancos pertenecientes a capitales extranjeros fueron 67\% menores en 2007 que en 2001 (a precios constantes). El impacto diferencial de la salida de la convertibilidad cobra aún más relevancia al considerar lo ocurrido con las entidades estatales y los bancos nacionales privados: mientras que las entidades estatales vieron reducidos sus ingresos entre 2001 y 2007 pero "sólo" un 23\% (frente al 67\% de las extranjeras), los bancos de capital privado nacional aumentaron sus ingresos un $30 \%$, obteniendo así niveles de ingresos reales superiores a los de los últimos años de la convertibilidad.

Sin duda, lo que más llama la atención es cómo quedó distribuido el mercado tras el abandono de la paridad cambiaria, ya que si antes las entidades estatales explicaban alrededor del $30 \%$ de los ingresos de las diez entidades bancarias

27 Entre estas grandes empresas de origen local productoras de bienes intermedios se destaca la única productora de aluminio del país (Aluar) y las siderúrgicas del grupo Techint.

28 Los trabajos de Azpiazu y Schorr (2010), CENDA (2007c) y Gigliani y Juncal (2007) señalan muy correctamente la ausencia de una verdadera política industrial que acompañe el mantenimiento de un tipo de cambio competitivo. 
Grática 3. Evolución de los ingresos por origen de capital de los grandes bancos, 1998-2007 (en millones de pesos de 2005)

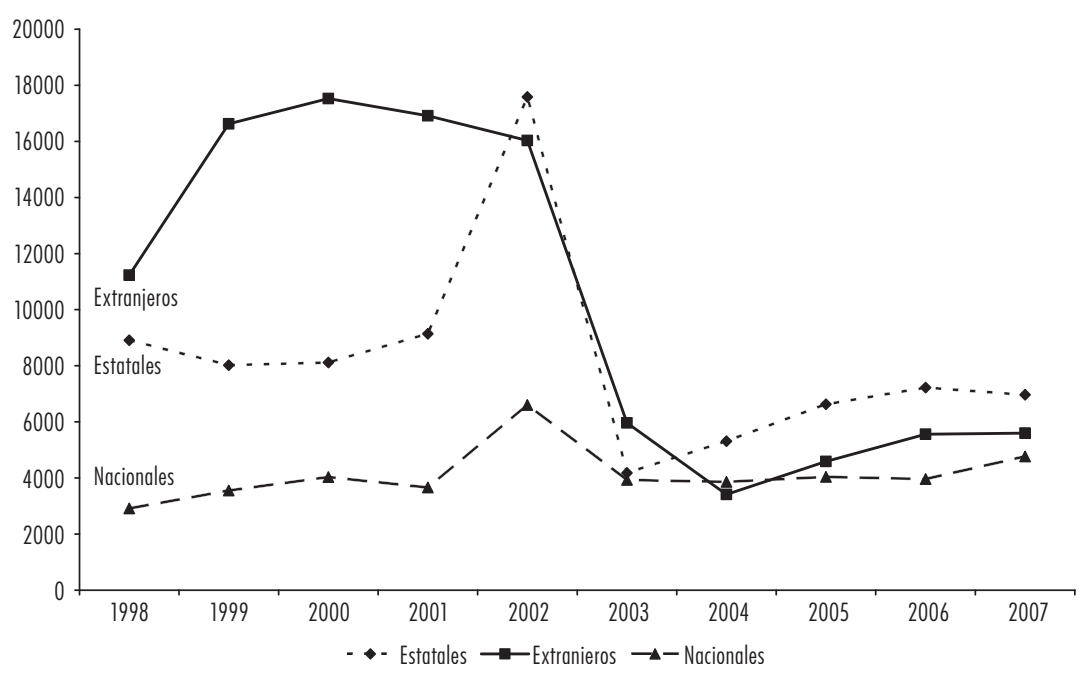

Fuente: Elaboración propia con base en BCRA, SAFJP y revistas Mercado y Prensa Económica.

más grandes, durante la posconvertibilidad éstas incrementaron su participación en 10 puntos porcentuales. Como contrapartida, los bancos extranjeros perdieron participación, pasando de representar el $57 \%$ de los ingresos de la cúpula financiera en 2001 al 32\% en 2007. Por último, en 2007 las entidades nacionales duplicaron su participación respecto a los últimos ańos de la convertibilidad.

En conclusión, se puede afirmar que a diferencia de lo ocurrido con las empresas del sector no financiero de la cúpula empresaria, en este caso sí hubo un cambio sustancial en el desempeńo de los distintos bancos según el origen del capital. Mientras que durante la segunda mitad de la década de los noventa el predominio de los bancos extranjeros fue indiscutido, a partir del abandono de la convertibilidad fueron los bancos estatales los principales protagonistas, a la par que creció significativamente la participación de los bancos privados nacionales. Estos cambios en los ingresos se debieron tanto a una mayor cantidad de entidades nacionales, ${ }^{29}$ como a un mejor desempeño individual de éstas respecto a las extranjeras. En este sentido, el achicamiento del mercado parece haber sido un aliciente para la partida

29 Entre 2002 y 2007 ingresaron en el ranking los bancos Ciudad, Credicoop, Macro y Patagonia Sudameris. 
o repliegue de entidades extranjeras, pasando las entidades nacionales a ocupar el espacio dejado por éstas. Asimismo, las políticas públicas adoptadas en este periodo parecen haber beneficiado mayormente a los bancos nacionales, tanto a los estatales como a los privados. Estos resultados no pueden ser escindidos del hecho de que, mientras que los bancos públicos, cooperativos y del interior (nucleados en la Asociación de Bancos Públicos y Privados de la República Argentina) se encuadraron políticamente detrás de los "sectores productivos" proclives a la modificación en el tipo de cambio a fines de 2001, los bancos extranjeros fueron los principales defensores del régimen de convertibilidad. ${ }^{30}$

\section{4. “GANADORES” Y “PERDEDORES” DENTRO DEL CAPITAL CONCENTRADO EN LA ARGENTINA}

Como es sabido, la tasa de ganancia es un dato clave que, además de ser el factor decisivo para impulsar la acumulación de capital, determina un conjunto de "ganadores" y "perdedores" en el interior del empresariado. Si bien con desigual intensidad, la crisis económica iniciada en 1998 en la Argentina tuvo un fuerte impacto en las ganancias en la mayor parte de las grandes empresas. Por el contrario, el fin de la convertibilidad implicó una heterogénea recuperación de las ganancias de las grandes firmas que dio lugar a una modificación en las rentabilidades relativas de los distintos sectores. ${ }^{31}$

Si bien el primer año tras el abandono de la convertibilidad (2002) fue el peor para el conjunto de las grandes empresas, la situación cambió a partir del año siguiente: desde 2003 la rentabilidad del conjunto de la cúpula empresaria se recuperó fuertemente, alcanzando niveles muy superiores incluso a los de los mejores años de la convertibilidad. Teniendo en cuenta los balances de las grandes empresas del sector no financiero, la tasa de rentabilidad promedio de la etapa 2003-2007 fue un 266\% más elevada que la registrada entre 1991 y 1998 y superó en un $52 \%$ a la de 1995, momento en el cual las grandes firmas obtuvieron el guarismo más elevado durante la década de los noventa. ${ }^{32}$

30 Al respecto ver Cobe (2009) y Wainer (2010).

31 Para tener un panorama más amplio sobre la evolución de las ganancias de los distintos sectores de la economía argentina en la posconvertibilidad véase CENDA (diciembre 2007a).

32 En 1995 las firmas que integran la cúpula empresaria obtuvieron una rentabilidad de 6.2\%. Entre 1991 y 1998, es decir, en los años previos a la última crisis, la rentabilidad promedio de la elite fue de $4 \%$. 
Por su parte, tras la salida de la convertibilidad los grandes bancos sufrieron una profunda y duradera caída en sus niveles rentabilidad, ya que la misma recién volvió a ser positiva en $2005 .{ }^{33} \mathrm{La}$ crisis del sistema financiero local, el abandono de la paridad cambiaria, la pesificación asimétrica ${ }^{34}$ y los cambios en los precios relativos hicieron que los bancos pasaran de ser unos de los principales beneficiarios de la política económica de los ańos noventa a unos de los más perjudicados. De todos modos cabe desatacar que partir de 2006 el nivel de rentabilidad de los grandes bancos superó al promedio de las grandes empresas no financieras, dando cuenta así de una recuperación tardía pero muy importante.

Gráfico 4. Rentabilidad de la cúpula empresaria, 1998-2007

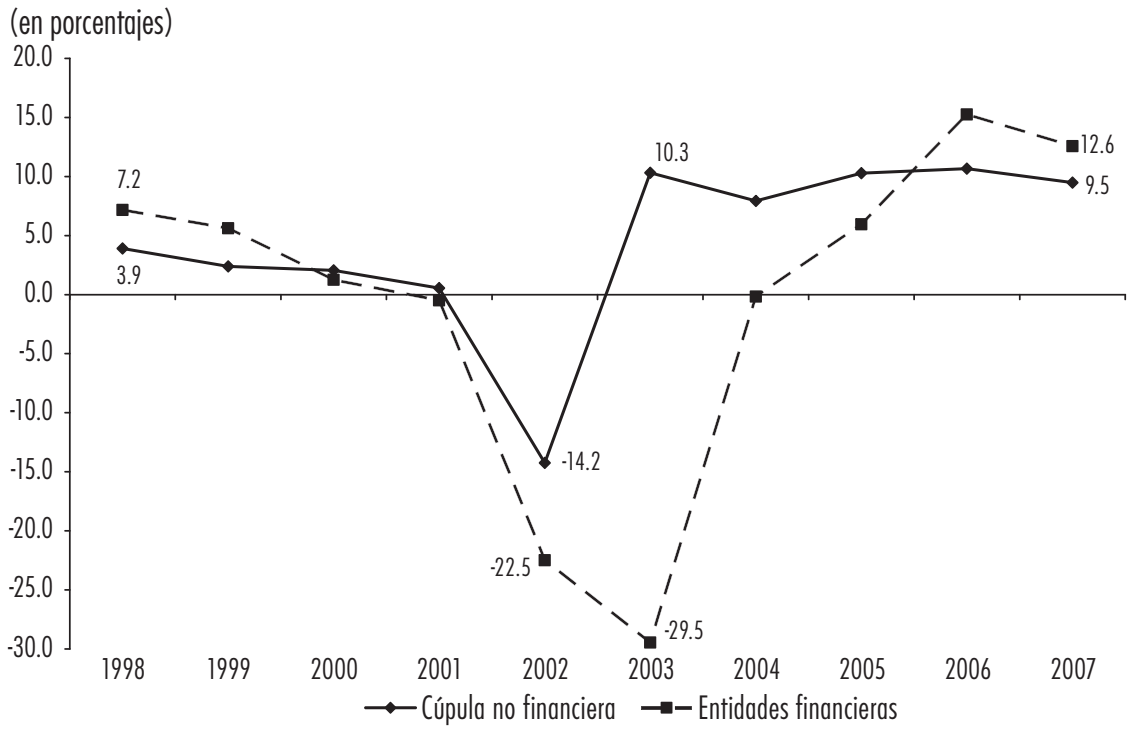

Fuente: Elaboración propia con base en información del Área de Economía y Tecnología de la FLACSO, las revistas Prensa Económica y Mercado y BCRA.

33 Para calcular la rentabilidad de las grandes entidades financieras se tuvo en cuenta la relación entre los resultados y los ingresos (ingresos financieros e ingresos por servicios).

34 Como forma de evitar un incumplimiento masivo de deudores, tras la devaluación se decidió realizar una pesificación asimétrica en la cual los ahorros en el sistema financiero local se "pesificaron" al nuevo tipo de cambio oficial (1,40 pesos por cada dólar) mientras que las deudas se "pesificaron" a la antigua paridad cambiaria (1 peso por dólar). Este "desfasaje" fue compensado por el Estado a las entidades financieras mediante la emisión de bonos. Al respecto consultar Cobe (2009) y Arceo y Wainer (2008). 
La temprana recuperación de la rentabilidad de las doscientas mayores compañías del sector no financiero estuvo motorizada por la declinación que experimentaron los salarios y los costos laborales a partir del año 2002. La inflación que trajo aparejada la devaluación de la moneda redujo significativamente ambas variables que, cabe aclarar, ya venían en declive desde el inicio mismo de la crisis económica en 1998. Por otro lado, también se dio conjuntamente un aumento de la productividad que, al no trasladarse a los salarios, produjo una mayor reducción de los costos laborales. ${ }^{35}$

En este sentido, la devaluación del peso argentino, por su magnitud, implicó una significativa transferencia de recursos desde el trabajo al capital. Pero, como se mencionó, la recuperación de las ganancias no fue para todos los sectores empresarios por igual, ya que, como se vio, los precios relativos favorecieron en mucha mayor medida a los productores de bienes que a los de servicios (Gráfica 5).

Gráfica 5. Evolución de la rentabilidad por sector de la cúpula empresaria (sector no financiero), 1998-2007 (en porcentajes)

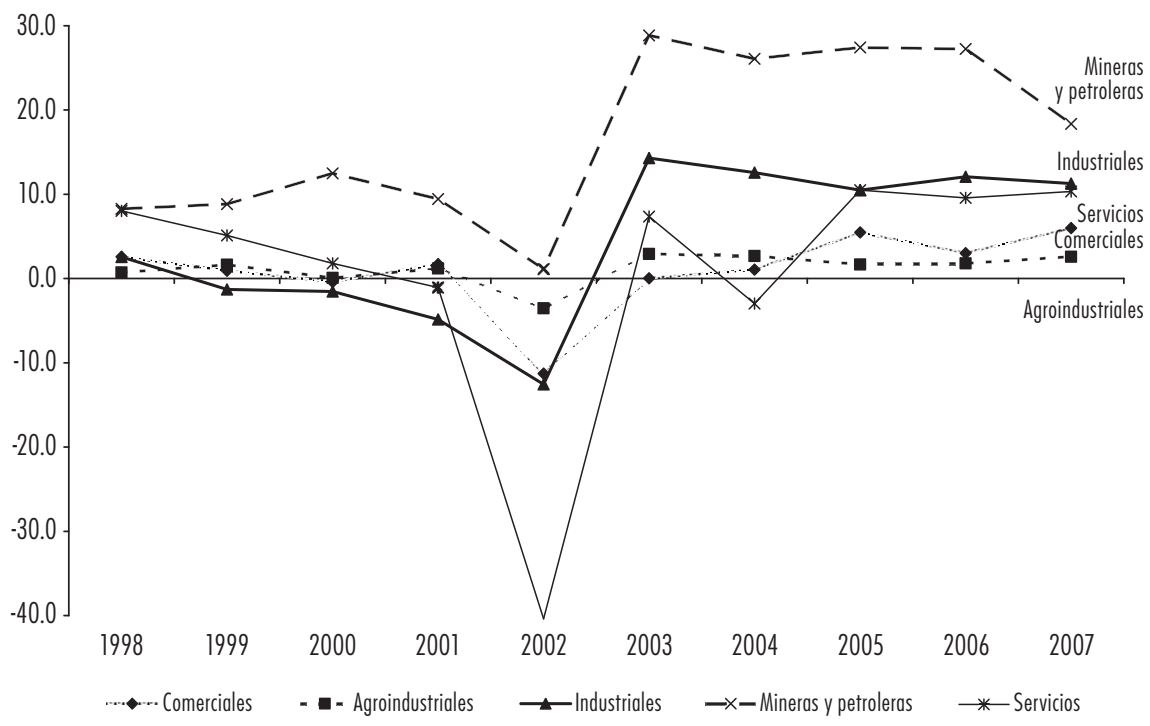

Fuente: Elaboración propia con base en información del Área de Economía y Tecnología de la Flacso, las revistas Prensa Económica y Mercado y BCRA.

35 Mientras que el salario medio de la economía en el año 2006 aún se encontraba un 7\% por debajo del de 2001, la productividad laboral superaba en más de 3\% a la de dicho año. Al respecto ver Arceo, Monsalvo, Schorr y Wainer (2008) y CENDA (diciembre 2007a). 
En efecto, tal como se observa en la Gráfica 5, el desempeño de los distintos tipos de empresas en términos de rentabilidad ha sido muy desigual. En primer lugar, se destaca la caída en la rentabilidad que sufrieron todas las grandes empresas en el año 2002, pero muy especialmente las firmas de servicios, que son las que obtuvieron la peor performance dentro de la cúpula empresaria.

Si bien prácticamente todas las grandes empresas obtuvieron malos resultados en 2002, para varias de ellas la situación mejoró sustancialmente a partir del año siguiente. A excepción de las entidades bancarias, el resto de las grandes empresas recuperó una ecuación económica positiva a partir de 2003, aunque con intensidades muy disímiles. La mayor rentabilidad relativa la siguieron detentando, al igual que durante los últimos ańos de la convertibilidad, las firmas petroleras y mineras, con niveles cercanos o superiores al 20\% entre 2003 y 2007. Este "excelente" desempeño se debió al carácter exportador de estas actividades, las cuales se vieron beneficiadas por la conjunción de un tipo de cambio devaluado y al alza en los precios internacionales del petróleo y los minerales.

En segundo lugar, se destaca la intensidad y el volumen de la recuperación de la rentabilidad de las firmas industriales de la cúpula empresaria, teniendo en cuenta que en los últimos años de la convertibilidad la misma fue crecientemente negativa. Con una rentabilidad superior al $10 \%$, las grandes empresas industriales quedaron como las más rentables de la posconvertibilidad luego de las mineras y petroleras. Si bien el objetivo no es comparar los valores de las respectivas rentabilidades, ${ }^{36}$ es importante subrayar los cambios en las posiciones producidos como consecuencia de la modificación del régimen macroeconómico a partir de 2002.

En el caso de las grandes firmas industriales, la recuperación de la rentabilidad se debió a la aguda alteración de la estructura de precios relativos y a la mencionada reducción de la tasa de interés real en el mercado local e internacional. Esta última permitió no tanto un mayor acceso al crédito, sino un incremento en la rentabilidad relativa de las inversiones productivas por sobre las financieras, conduciendo de esta manera a una asignación del excedente distinta a la predominante durante la década de los noventa. Además de desestimular la

36 No puede realizarse una comparación fehaciente de las rentabilidades en términos absolutos ya que las distintas velocidades de rotación del capital pueden hacer variar la tasa de ganancia entre los distintos sectores. Muy probablemente la rotación del capital en la mayor parte de la industria manufacturera sea bastante mayor que en las inversiones mineras y petroleras, con lo cual seguramente las diferencias serían menores de considerar las tasas de ganancia anuales sobre el capital adelantado. En este sentido, la velocidad de rotación influye en la tasa de ganancia, ya que un mismo capital puede rotar una o varias veces por ańo, y por lo tanto, el reflujo del mismo varía. Al respecto ver Marx (1997). 
inversión financiera, la menor tasa de interés implica una menor punción sobre el capital productivo, con lo cual el excedente generado por este último es retenido en mayor medida dentro del propio sector, lo que constituye una diferencia muy significativa respecto a lo ocurrido durante la convertibilidad.

El sustancial aumento de las ventas de la industria local permitió una mayor utilización de la capacidad instalada, ${ }^{37}$ lo cual determinó una reducción de los costos unitarios. Al contar con una amplia capacidad ociosa, la reactivación de la producción se pudo sostener básicamente mediante la incorporación de una mayor cantidad de trabajadores y con una superior carga horaria de los mismos. Asimismo, como se señaló, el costo de la mano de obra en la industria manufacturera cayó significativamente tras la devaluación en $2002 .{ }^{38}$ Esta conjunción de factores -mayor utilización de la capacidad instalada y reducción de los costos laborales- hizo posible que aumentasen los márgenes de ganancia en relación a la inversión realizada.

Si bien el congelamiento de las tarifas de los servicios públicos dispuesto por la misma ley que determinó el fin de la convertibilidad ${ }^{39}$ benefició, en términos de costos, a las empresas industriales, a su vez condujo a una merma en la rentabilidad de las firmas de servicios públicos. ${ }^{40}$ No obstante, a partir de 2003 también se vislumbró una recuperación en el nivel de rentabilidad de las grandes empresas de servicios, aunque no fue sino hasta 2005 cuando lograron niveles de rentabilidad superiores a los del inicio de la crisis de la convertibilidad. Esta tardía recuperación se vio favorecida en parte por el aumento de tarifas para los grandes usuarios industriales y comerciales, por la aplicación de subsidios estatales y, sobre todo, por la mayor demanda de servicios que trajo aparejado el crecimiento de la economía.

En el caso de las empresas agroindustriales, la rentabilidad se recuperó fuertemente a partir de 2003, mostrando niveles superiores a los de los últimos años

37 La utilización de la capacidad instalada promedio para la industria manufacturera pasó del $56 \%$ en 2002 al $74 \%$ en 2007 (INDEC).

38 Entre 2001 y 2002 el costo laboral manufacturero cayó 36\% (Arceo, Monsalvo, Schorr y Wainer, 2008).

39 La Ley de Emergencia Pública y de Reforma del Régimen Cambiario No 25.561 del 6 de Enero de 2002 suspendió todos los mecanismos indexatorios de los contratos de los servicios públicos y estableció que las tarifas debían quedar en pesos al tipo de cambio previo a la devaluación ( $\$ 1=\mathrm{US} \$ 1)$.

40 Debe tenerse en cuenta que las empresas de servicios públicos tienen un peso decisivo en el conjunto de las compañías de servicios en la cúpula empresaria: entre 2002 y 2007 aproximadamente la mitad de las ventas de estas últimas fueron explicadas por las firmas de servicios públicos privatizadas. 
de la década de $1990 .{ }^{41} \mathrm{Al}$ igual que las firmas petroleras y mineras, al ser empresas con capacidad exportadora se vieron favorecidas por la devaluación de la moneda en 2002. Sin embargo, la modificación cambiaria no fue el único factor que incidió en la mejora de la rentabilidad de las firmas agroindustriales ya que, como se mencionó anteriormente, también se dio conjuntamente un aumento de precios de los principales commodities a nivel mundial, incluidos los de origen agropecuario.

Por último, en el caso de las firmas comerciales, tras un muy mal desempeño durante los últimos años de la convertibilidad y una fuerte caída en 2002, las mismas lograron recuperar niveles de rentabilidad positivos a partir de $2003 \mathrm{al}$ compás de la reactivación del mercado interno y el incremento de las exportaciones de cereales y oleaginosas. ${ }^{42}$

En definitiva se puede sostener que el abandono de la convertibilidad generó cambios macroeconómicos que tuvieron impactos desiguales en la evolución de la rentabilidad de las distintas fracciones del gran capital en la Argentina. En este sentido, se destaca una recuperación importante de la tasa de ganancia de las firmas industriales, un crecimiento exponencial de la rentabilidad de las empresas petroleras y mineras y una significativa pérdida de rentabilidad de las entidades financieras y las empresas de servicios durante los primeros años del nuevo régimen macroeconómico.

No obstante, a la luz de los resultados obtenidos por todas las grandes empresas en los últimos años, se puede afirmar que el abandono de la convertibilidad ofreció una salida para el capital en su conjunto, ya que permitió recomponer el ciclo de acumulación frente a un esquema que se mostraba agotado. En este sentido, si bien algunas grandes empresas se vieron más perjudicadas o menos favorecidas por los cambios macroeconómicos acaecidos en 2002 en relación a otras, lo cierto es que la recuperación de niveles de rentabilidad positivos a partir de 2005 tanto para las empresas de servicios como para las entidades financieras de la cúpula empresaria permite suponer que la devaluación de la moneda terminó beneficiando al gran capital en su conjunto.

41 Cabe mencionar que los bajos niveles absolutos de rentabilidad de las empresas agroindustriales pueden esconder una tasa de ganancia anual más abultada dada la mayor velocidad de rotación del capital, por ejemplo, respecto a la industria manufacturera y la construcción.

$42 \mathrm{Al}$ respecto cabe hacer la misma aclaración realizada para las firmas agroindustriales sobre los niveles absolutos de rentabilidad y la velocidad de rotación del capital; es decir, bajos niveles de rentabilidad absoluta no implican que se hayan dado menores tasas de ganancia sino que pueden esconder una rotación más veloz del capital global adelantado. 


\section{COMENTARIOS FINALES}

La situación relativa de las grandes empresas en la Argentina se ha visto modificada a partir de los cambios introducidos en la política económica con el abandono del régimen de convertibilidad. En este sentido, se ha operado un cambio importante respecto a lo ocurrido durante la convertibilidad, generándose así un nuevo esquema de "ganadores" y "perdedores" (siempre en términos relativos). Sin embargo, no todas las fracciones vieron alterada de manera tan significativa su situación relativa. Si bien se vieron muy favorecidas por la devaluación de la moneda en 2002, tanto las firmas agroindustriales como las comercializadoras de la producción agropecuaria ya habían tenido un buen desempeño durante la década de los noventa, acorde al perfil productivo "reprimarizado" que fue adoptando la Argentina. Para estas subfracciones, cuya situación se encontraba consolidada de antemano, la modificación cambiaria no fue determinante en sus niveles de competitividad, aunque les permitió obtener ganancias extraordinarias.

A pesar de los cambios registrados en la cúpula empresaria, lo que no se ha modificado -sino más bien todo lo contrario- es el predominio del capital extranjero entre las grandes firmas del sector no financiero. Si bien desde 2002 los distintos gobiernos han hecho declaraciones en favor de la reconstrucción de una "burguesía nacional", la presencia del capital extranjero se ha consolidado en casi todos los tipos de firmas. La excepción en este sentido estuvo dada, como se vio, por lo ocurrido con las entidades financieras. Mientras que en el resto de la cúpula empresaria argentina el capital extranjero continuó aumentando su participación, entre las grandes entidades bancarias perdió posiciones a manos del capital nacional, tanto privado como estatal. Si bien entre las firmas de servicios públicos también se ha producido cierta "nacionalización" (entendida ésta como la transferencia del capital de una empresa extranjera a propietarios locales), ésta ha sido muy acotada y no ha logrado cambiar sustancialmente la relación de fuerzas vigente entre el capital nacional y el extranjero. ${ }^{43}$

43 Dentro del acotado proceso de nacionalización parcial de algunas empresas de servicios públicos se destacan los ingresos del grupo local Werthein a la empresa de telefonía Telecom (en sociedad con Telecom Italia) y del grupo Pampa Holding en empresas generadoras, transmisoras y distribuidoras de energía eléctrica. Otros casos de reingreso de capitales nacionales se dieron en empresas de servicios públicos provinciales. $\mathrm{Al}$ respecto consultar Azpiazu, Bonofiglio y Nahón (2008). 
Parecería ser que entre aquellas fracciones capitalistas que se vieron mayormente perjudicadas por la salida de la convertibilidad se abrió un espacio para el reingreso del capital nacional, aunque claro está, en una situación muy distinta a la imperante durante los ańos noventa, ya que el negocio en estos sectores se vio alterado. En este sentido, por más que hayan cambiado parcialmente los liderazgos empresarios, la dinámica general del gran capital siguió estando dominada por las empresas trasnacionales.

Esto tiene consecuencias significativas en lo que hace a un "proyecto de país" conducido por los sectores dominantes. Parece difícil que pueda impulsarse un desarrollo liderado por la "burguesía nacional" dado que ésta, al menos hasta el momento, carece de base de sustentación económica. ${ }^{44} \mathrm{Si}$ bien la situación del sector productivo ha mejorado considerablemente durante la posconvertibilidad, la modificación del tipo de cambio no parece haber sido un aliciente suficiente para generar un proyecto de desarrollo que le otorgue un lugar significativo a los actores económicos nacionales menos concentrados.

\section{BIBLIOGRAFÍA}

Arceo, Enrique, "El impacto de la globalización en la periferia y las nuevas y viejas formas de dependencia en América Latina", en Cuadernos del CENDES, núm. 60, Caracas, CENDES-UCV, 2005, pp. 25-62.

Arceo, Enrique, ALCA, Neoliberalismo y Nuevo Pacto Colonial, Buenos Aires, IEF-CTA, 2001.

Arceo, Nicolás, Ana Paula Monsalvo, Martín Schorr y Andrés Wainer, Empleo y salarios en la Argentina. Una visión de largo plazo, Buenos Aires, Capital Intelectual, 2008.

Arceo, Nicolás y Andrés Wainer, La crisis de la deuda y el default. Los distintos intereses en torno a la renegociación de la deuda pública, Buenos Aires, Documento de Trabajo núm. 20, AEyT-FLACso, 2008.

Azpiazu, Daniel, Eduardo Basualdo y Bernardo Kosacoff, "Las empresas transnacionales en la Argentina 1976-1986", en Revista de la CEPAL, núm. 28, Santiago de Chile, CEPAL, 1986, pp. 99-130.

Azpiazu, Daniel, Eduardo Basualdo, Nicolás Arceo y Andrés Wainer, Transformaciones estructurales de la economía argentina. Una aproximación a partir del panel de grandes empresas, 1991-2005, Buenos Aires, PNUD, 2009.

44 Aunque desde una perspectiva algo diferente, Katz (2007) arriba a similares conclusiones respecto a la inexistencia de una burguesía "nacional" en la Argentina actual. 
Azpiazu, Daniel, Nicolás Bonofiglio y Carolina Nahón, Agua y energía. Mapa de situación y problemáticas regulatorias de los servicios públicos en el interior del pais, Buenos Aires, Documento de Trabajo núm. 18, AEyT-FLACso, 2008.

Azpiazu, Daniel, Karina Forcinito y Martín Schorr, Privatizaciones en la Argentina. Renegociación permanente, consolidación de privilegios, ganancias extraordinarias y captura institucional, Buenos Aires, Documento de Trabajo núm. 2, AEYT-FLACSO, 2001.

Azpiazu, Daniel, Roberto Bisang y Bernardo Kosacoff, "Industrialización y exportación de manufacturas en la Argentina. Evolución estructural y apertura exportadora (1973-1986)", en Boletín Informativo Techint, núm. 253, Buenos Aires, Organización Techint, 1988, pp. 25-75.

Azpiazu, Daniel y Martín Schorr, "La industria argentina en la posconvertibilidad: reactivación y legados del neoliberalismo", en Problemas del Desarrollo, Vol. 41, núm. 161, México, IIEC-UnAm, abril-junio de 2010, pp. 111-139.

Basualdo, Eduardo, Estudios de Economía Argentina, Buenos Aires, Siglo XXI Editores, 2006.

Bekerman, Marta y Diego Cerdeiro, "Crisis y patrón de especialización comercial en economías emergentes. El caso de Argentina”, en Problemas del Desarrollo, Vol. 38, núm. 150, México, IIEC-Unam, julio-septiembre de 2007, pp. 133-165.

Bisang, Roberto, "El desarrollo agropecuario en las últimas décadas: ¿volver a creer?", en Kosacoff (coomp.): Crisis, recuperación y nuevos dilemas. La economía argentina 2002-2007, Buenos Aires, CEPAL, 2007.

Bleger, Leonardo, "El proceso de concentración y extranjerización del sistema bancario argentino durante los 90", en Boletín Informativo Techint, núm. 301, Buenos Aires, Organización Techint, 2000, pp. 21-39.

Braun, Oscar, "Desarrollo del capital monopolista en la Argentina", en Braun (comp.), El capitalismo argentino en crisis, Buenos Aires, Siglo XXI, 1975.

Braun, Oscar y Leonard Joy, "Un modelo de estancamiento económico. Estudio de caso sobre la economía argentina”, en Desarrollo Económico, Vol. 20, núm. 80, Buenos Aires, IDES, enero-marzo de 1981, pp. 585-604.

Burachik, Gustavo, "Extranjerización de grandes empresas en Argentina", en Problemas del Desarrollo, vol. 41, núm. 160, México, IIEC-UnAM, enero-marzo de 2010, pp. 109-133.

Centro de Estudios para el Desarrollo Argentino (CENDA), "La economía local en perspectiva latinoamericana: rasgos distintivos del crecimiento argentino", en Notas de la economía argentina, núm. 03, Buenos Aires, junio 2007, pp. 03-09. Centro de Estudios para el Desarrollo Argentino (CENDA), "La trayectoria de las ganancias después de la devaluación: la "caja negra" del crecimiento 
argentino", en Notas de la economía argentina, núm. 04, Buenos Aires, diciembre 2007(a), pp. 04-12.

Centro de Estudios para el Desarrollo Argentino (CENDA), “¿Y dónde está el piloto? El crecimiento de la industria sin política industrial”, en Notas de la economía argentina, núm. 04, Buenos Aires, diciembre 2007(b), pp. 13-20.

Centro de Investigación y Formación de la República Argentina, Transformaciones estructurales en al agro pampeano. La consolidación del bloque agrario en la Argentina, Buenos Aires, Documento de Trabajo núm. 1, CIFRA, 2009.

Cobe, Lorena, La salida de la convertibilidad. Los bancos y la pesificación, Buenos Aires, Capital Intelectual, 2009.

Cooney, Paul y Abelardo Mariña Flores, "Nuevos mecanismos de subordinación al capital financiero mundial: deuda externa e interna en Brasil y México", en Anales del IV Coloquio Internacional de la Sociedad Latinoamericana de Economía Política y Pensamiento Crítico, Buenos Aires, SEPLA, 2008.

Cooney, Paul, "Dos décadas de neoliberalismo en México-Resultados y desafíos", en XXXV Encontro Nacional de Economia, Recife, ANPEC, 2007a.

Cooney, Paul, "Brasil: Apertura comercial y financiera desde 1989", en III Coloquio Internacional de Sociedad Latinoamericana de Economía Politica y Pensamiento Crítico, Caracas, sepla, 2007b.

Damill, Mario y Roberto Frenkel, Las políticas macroeconómicas en la evolución reciente de la economía argentina, Buenos Aires, Nuevos Documentos Cedes, núm. 65, 2009.

Diamand, Marcelo, Doctrinas económicas, desarrollo e independencia, Buenos Aires, Paidós, 1973.

Gigliani, Guillermo y Santiago Juncal, "La actual fase industrial argentina y los límites del modelo”, en Anuario EDI, núm. 3, Buenos Aires, EDI, abril 2007, pp. 140-155.

González, Mariana y Javier Rodríguez, "El auge exportador y el sector agropecuario argentino", en Anuario EDI, núm. 3, Buenos Aires, EDI, abril 2007, pp. 172-190.

Katz, Claudio, "El giro en la economía argentina", en Anuario EDI, núm. 3, Buenos Aires, EDI, abril 2007, pp. 93-107.

Lanteri, Luis, "Argentina y la reversión de los déficits del sector externo", en Problemas del Desarrollo, Vol. 40, núm. 159, México, IIEC-UnAM, octubrediciembre de 2009, pp. 119-141.

Lozano, Claudio, Ana Rameri y Tomás Raffo, Las transformaciones en la cúpula empresarial durante la última década: Nuevos liderazgos, similar patrón productivo y mayor extranjerización, Buenos Aires, Documento publicado 
por el Instituto de Estudios y Formación de la Central de los Trabajadores Argentinos (СтA), 2009.

Peralta Ramos, Mónica, La economía política argentina: poder y clases sociales (1930-2006), Buenos Aires, Fondo de Cultura Económica, 2007.

Schorr, Martín y Andrés Wainer, "Argentina: ¿Muerte y resurrección? Notas sobre la relación entre economía y política en la transición del 'modelo de los noventa' al de 'dólar alto'”, en Realidad Económica, núm. 211, Buenos Aires, IADE, abril-mayo de 2005, pp. 32-65.

Sourrouille, Juan, "El impacto de las empresas transnacionales sobre el empleo y los ingresos: el caso de la Argentina”, en Programa Mundial de Empleo, Buenos Aires, Organización Internacional del Trabajo (огт), abril de 1976.

Torre, Juan Carlos y Pablo Gerchunoff, "La política de liberalización económica en la administración Menem”, en Desarrollo Económico, Vol. 36, núm. 143, Buenos Aires, IDES, octubre-diciembre de 1996, pp. 733-768.

Varesi, Gastón, "La Argentina posconvertibilidad: modo de acumulación", en Problemas del Desarrollo, Vol. 41, núm. 161, México, IIEC-UnAM, abril-junio de 2010, pp. 141-152.

Vidal, Gregorio (coomp.), Los procesos de integración en América y las opciones de México para el desarrollo, México, Porrúa, 2008.

Wainer, Andrés, Clase dominante, hegemonía y modos de acumulación. La reconfiguración de las relaciones de fuerza al interior de la burguesía durante la crisis y salida de la convertibilidad (1998-2003), Tesis de doctorado, FLACSO-Sede Argentina, 2010. 